\title{
Maximal intestinal absorption of digoxin, and its relation to steady state plasma concentration
}

\author{
Brian F. Johnson and Carole Bye \\ From the Clinical Research Division, Wellcome Research Laboratories, Langley Court, Beckenham, Kent
}

In a group of 8 volunteers, peak plasma digoxin concentrations and areas under 80-hour plasma concentration curves were significantly greater after I $\mathrm{mg}$ digoxin in paediatric elixir than after four $0.25 \mathrm{mg}$ tablets. Mean cumulative urinary excretion of digoxin over I2 days was 46.4 per cent after tablets, 53.6 per cent after elixir, and 70.8 per cent after intravenous injection. Mean percentage absorption was estimated to be 63 per cent from tablets and 75 per cent from elixir, but considerable between-subject variation was noted. Individual estimates of percentage absorption were significantly correlated with plasma concentrations in the steady state. Computer programmes to relate steady state plasma concentration to oral digoxin dosage take no account of subjective absorptive capacity, are limited to gross approximations, and cannot replace determination of plasma concentration to assess the degree of digitalization.

Study of the human pharmacokinetics of digoxin was limited for many years by the absence of reasonable techniques of measurement. However, using slowing of the ventricular rate in patients with atrial fibrillation as a measure of efficacy, it was suggested that about 50 per cent of ingested digoxin was absorbed (Gold et al., 1953). Subsequent studies with tritiated digoxin (Doherty, Perkins, and Mitchell, 196r) or with unlabelled drug measured by radioimmunoassay (Huffman and Azarnoff, 1972) have suggested that digoxin is better absorbed than previously supposed, and that recommended doses should be reduced.

However, some studies have utilized tablets and others alcoholic solution. Further, it is now known that there is great variability in the absorption of digoxin from different brands of tablets (Lindenbaum et al., 197I) and that this variability is related to the rate of dissolution of digoxin in tablets (Lindenbaum et al., I973; Johnson et al., 1973). Before it can be transported across the intestine, digoxin must dissolve in intestinal fluids, and the technique of determining rate of tablet dissolution in water simulates this process. Therefore experiments were undertaken to compare the maximal percentage absorption from digoxin elixir and tablets of rapid dissolution rate.

\section{Materials and methods}

\section{Treatments}

The tablets administered were standard $0.25 \mathrm{mg}$ Received 30 July 1974 . 'lanoxin' (digoxin) tablets of batch $1484 \mathrm{X}$, with a dissolution rate of 79 per cent in 15 minutes and 98 per cent in 60 minutes in a previously described dissolution apparatus (Johnson et al., 1973).

Digoxin elixir was the standard paediatric 'lanoxin' elixir, containing $0.05 \mathrm{mg}$ digoxin $/ \mathrm{ml}$ in IO per cent alcohol, 5 per cent propylene glycol, and 30 per cent sucrose solution. The injection fluid was the standard intravenous 'lanoxin' preparation of $0.25 \mathrm{mg}$ digoxin $/ \mathrm{ml}$ in ro per cent alcohol and 40 per cent propylene glycol solution. $3 \mathrm{ml}$ was diluted by $17 \mathrm{ml}$ normal saline immediately before intravenous injection over a period of 3 minutes.

\section{Procedure}

A group of 8 healthy volunteers aged 23 to 44 years and weighing 50.8 to $83 \mathrm{~kg}$ underwent study on five separate occasions, each separated by at least two weeks. All had normal creatinine clearance. Single dose treatments were administered in random sequence, and consisted of 6 standard tablets ( $1.5 \mathrm{mg}), 4$ standard tablets $(\mathrm{I} \cdot 0 \mathrm{mg}$ ), $0.75 \mathrm{mg}$ intravenous injection fluid, and $\mathrm{r} .0 \mathrm{mg}$ elixir, each being administered after an overnight fast. Blood was obtained at 30-minute intervals for 3 hours, then 2-hour intervals for a further 6 hours, and at $12,24,28,32,48$, $52,56,72,76$, and 80 hours after administration. All urine produced was collected for 12 days after each treatment, other than after the larger dose of standard tablets when collection was concluded after 5 days. During the first 24 hours, urine was divided into three consecutive 4-hour, and one 12-hour period.

The fifth treatment schedule consisted of one $0.25 \mathrm{mg}$ standard tablet at $9.0 \mathrm{a} . \mathrm{m}$. and $9.0 \mathrm{p} . \mathrm{m}$. each day for 14 days and at 9.0 a.m. on the 15 th day, i.e. 2 tablets daily for 14 days $+I$ on the 15 th day. Blood was obtained at 8.50 
a.m. on days I I and I5, and after the last tablet blood was collected for a complete blood profile as in the acute studies. Urine was collected during one dosage interval of 12 hours on day II. After the last tablet at 9.0 a.m. on day 15, urine collection continued for 5 days.

\section{Digoxin assay and statistical evaluation}

Plasma was quickly separated from blood samples and stored at $4^{\circ} \mathrm{C}$. Aliquots of urine were obtained and similarly stored as soon as available. Digoxin was determined in all samples in triplicate by radioimmunoassay (Lader et al., 1972) using an iodinated tyrosine derivative of digoxin as the tracer. Standards and reference human plasma or urine were included in each assay run. From repeated assay of reference samples and plasma samples to which known amounts of digoxin have been added, a coefficient of variation of approximately 6 per cent was calculated.

Statistical significance of differences was assessed by parametric analysis of variance.

\section{Results}

As shown in Fig. I, mean peak plasma concentration was significantly greater $(P<0.01)$ after elixir than after 4 standard tablets ( $\mathrm{I} \mathrm{mg}$ ), respective values being 7.0 and $3.2 \mathrm{ng} / \mathrm{ml}$. The mean peak level after $\mathrm{r} \cdot 0 \mathrm{mg}$ elixir was not significantly different from that after 6 tablets ( $1 \cdot 5 \mathrm{mg}$ ), which was $6.0 \mathrm{ng} / \mathrm{ml}$. For each oral treatment, mean peak levels occurred one hour after administration.

After the first 5 hours, differences between plasma concentrations after elixir and after 4 tablets were minor. After ingestion of a drug, the shape of the plasma concentration curve is specific both for the drug and the individual. However, for that individual, both the height and duration of measurable plasma concentrations are dependent upon the quantity of drug absorbed. Rapidly absorbed drugs will tend to produce high peak concentrations, whereas sustained absorption will prolong the period for which the drug can be measured in plasma. Determination of the area under a plasma concentration curve incorporates both height and duration, and is therefore an estimate of overall absorption.

Comparison of infinite areas under concentration curves is a reliable method of assessing the efficiency of absorption, if rate of drug elimination remains constant. In this study plasma concentrations were close to zero at 80 hours, so the area under the plasma curve up to 80 hours is a good estimate of the area at infinite time. For each subject-occasion, the area under the entire plasma concentration curve was mathematically determined by the trapezium method, and group mean values derived for each treatment. With the trapezium method, the total area is divided into a series of trapezia in which one side is the time between adjacent plasma sampling points, and the parallel sides are the plasma concentrations at these points. A close approximation of the total area is obtained by summing the areas calculated for each trapezium. Significant differences $(\mathbf{P}<0.05)$ between areas under plasma concentration curves were noted over the 80 hours after each ingested treatment, respective mean values for 4 tablets, elixir, and 6 tablets being $47 \cdot 2,63 \cdot 3$, and $83 \cdot 3(\mathrm{ng} / \mathrm{ml}) \times \mathrm{hr}$.

As seen in Fig. 2 and 3, the plasma concentration curve from 5 hours after intravenous injection of $0.75 \mathrm{mg}$ digoxin was identical to that after elixir, and intermediate between those of the two doses of tablets. Percentage absorption of digoxin was calculated by expressing each individual area under curve measurement after oral administration as a proportion of that after intravenous injection, with

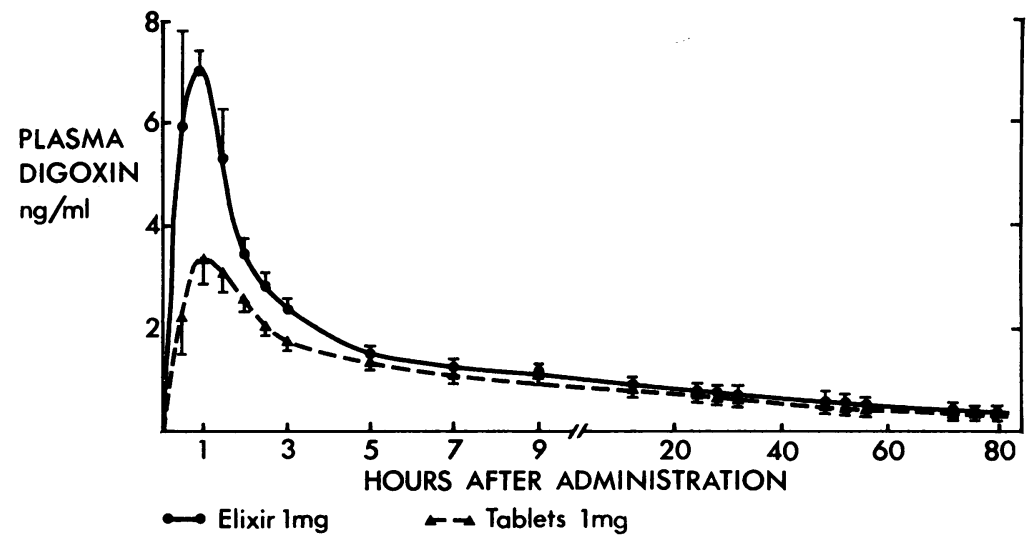

FIG. I Comparison of mean plasma concentration curves ( \pm SEM) after $I \cdot 0$ mg digoxin administered as paediatric elixir or 'lanoxin' tablets. 


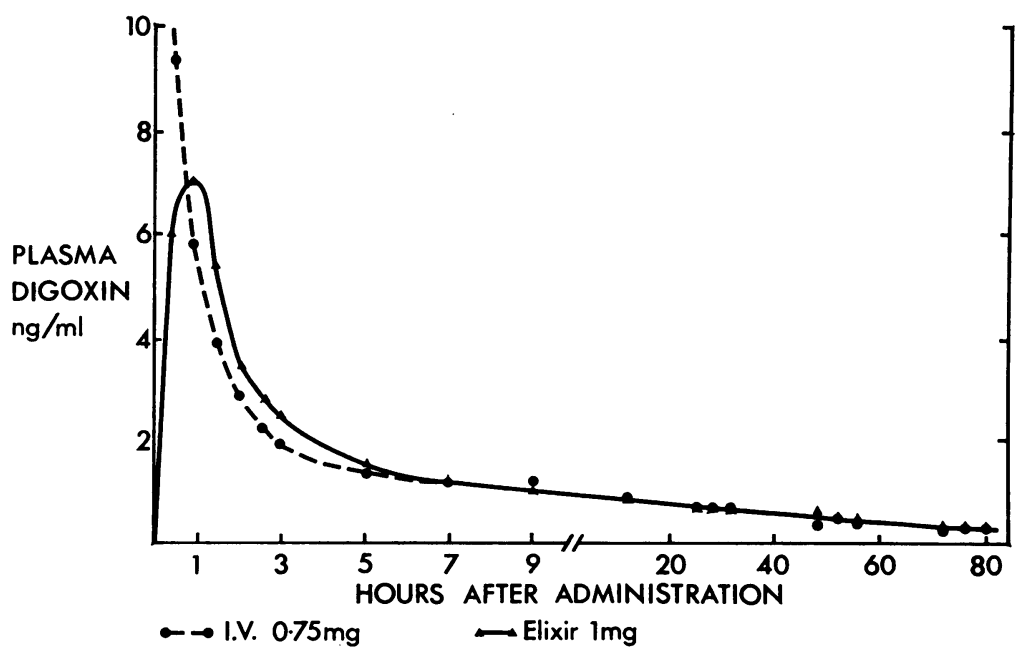

FIG. 2 Curve of mean plasma digoxin concentration after $\mathrm{I} \cdot 0 \mathrm{mg}$ as paediatric elixir compared with that after $0.75 \mathrm{mg}$ injected intravenously.

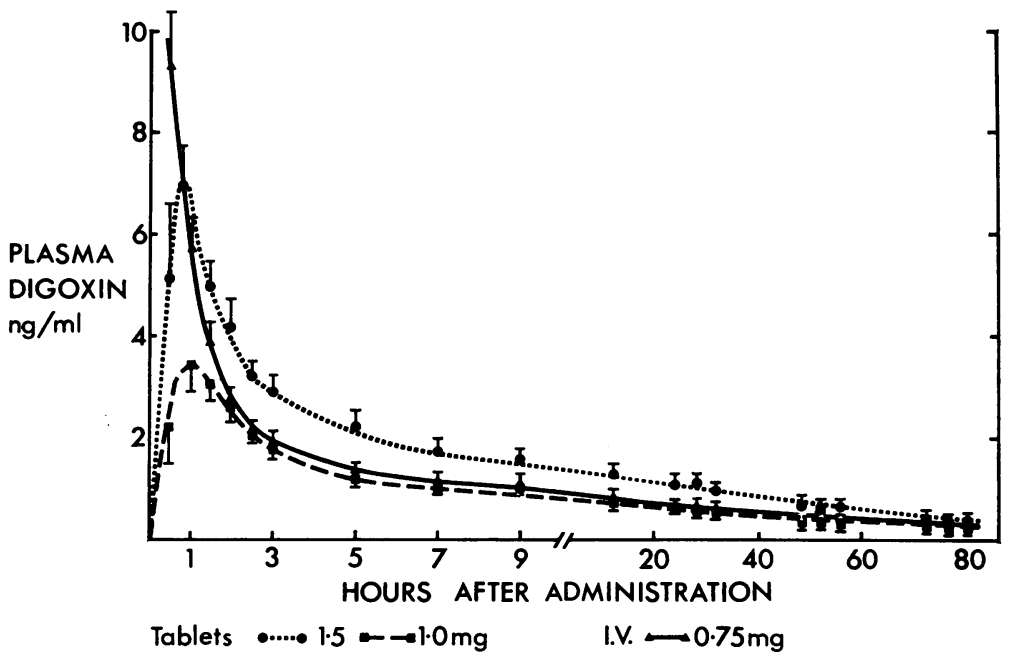

FIG. 3 Curves of mean plasma digoxin concentration ( $\pm S E M$ ) after $I \cdot 5$ and $I \cdot 0 \mathrm{mg}$ doses of

'lanoxin' tablets compared with that after $0.75 \mathrm{mg}$ injected intravenously.

correction for differences in administered dose. For example in one subject, respective area under curve values of 69.7 and $66.3(\mathrm{ng} / \mathrm{ml}) \times \mathrm{hr}$ were obtained after administration of $\mathrm{I} \cdot 0 \mathrm{mg}$ of elixir by mouth and $0.75 \mathrm{mg}$ intravenously. For this subject, percentage absorption of digoxin from elixir was calculated as

$$
\frac{(69 \cdot 7 / 1 \cdot 0)}{(66 \cdot 3 / 0 \cdot 75)} \times 100=79 \text { per cent }
$$

Group mean values were derived for both tablet occasions together, and for elixir. The mean area under curve measurement after the injection was 6r.I $(\mathrm{ng} / \mathrm{ml}) \times \mathrm{hr}$, and mean percentage absorption of digoxin could be calculated as approximately 64 per cent from tablets and $\mathbf{7 8}$ per cent from elixir.

Cumulative urinary excretion of digoxin after each mode of administration is compared in Fig. 4. Mean percentage excretion of administered dose for 4 tablets, elixir, and injection was, respectively, $46.4,53.6$, and 70.8 per cent, only that after intravenous administration being significantly different 
from the others $(P<0.01)$. However, the proportion of administered dose excreted during the initial 8 hours was significantly lower $(P<0.05)$ after tablets, whereas there was no difference between elixir and injection. Only at 24 and 48 hours were cumulative excretions after all treatments significantly different $(\mathbf{P}<0.05)$. Ranges of percentage excretion of administered dose after injection, tablets, or elixir were respectively 64 to 81 per cent, 35 to 60 per cent, and 39 to 76 per cent. For individual subjects, there was a correlation between the percentages of administered dose excreted after tablets and elixir $(r=0.8 \mathrm{r}, \mathrm{P}<0.05)$. For each individual, digoxin absorption was calculated by expressing the percentage of orally administered dose excreted as a proportion of that percentage excreted after intravenous injection. Between subjects, percentage absorption ranged from 44 to 82 per cent from tablets, and 57 to 96 per cent from elixir, with mean values of 63 and 75 per cent, respectively. For individual subjects, there was a significant correlation between measures of percentage absorption determined by the area under curve and urinary excretion methods $(r=0.87$, $P<0.01$ ).

In the steady state, plasma concentrations on day 15, I2 hours after a tablet, ranged from 0.7 to $\mathrm{I} \cdot 55 \mathrm{ng} / \mathrm{ml}$. Percentage urinary excretion of the administered dose of one tablet was calculated for each subject during the interval of 12 hours between administration of two consecutive tablets. Within the group, percentage urinary excretion ranged from 31 to 61 per cent. For individuals, percentage of administered dose excreted during a dosage interval in the steady state correlated with percentage of administered dose excreted over 12 days after the single dose of four tablets $(r=0.77$, $P<0.05$ ).

It was assumed that digoxin excretion was according to a simple one-compartment open model, in which the cumulative amount of measurable digoxin, $U(t)$, excreted in urine in time $t$ was related to the total amount of measurable digoxin, $U^{\infty}$, which was ultimately excreted in urine, by the relation

$$
U(t)=U^{\infty}\left(I-e^{-k t}\right)
$$

where $k$ is the elimination rate constant. This can be rewritten as

$$
\log _{\theta}\left[U^{\infty}-U(t)\right]=k t+\log _{\theta} U^{\infty}
$$

where $U^{\infty}-U(t)$ represents residual digoxin remaining to be excreted in urine. Calculations of this residual quantity were made after each collection period using the cumulative excretion at 12 days as the best estimate of $U^{\infty}$, and $k$ was estimated by linear regression of logarithmic values of the residual quantity against time. The regression calculations showed an excellent fit with the kinetic model in each subject-occasion. Individual half-lives of urinary elimination were calculated as $\log _{e} 2(=0.6932)$ divided by $k$. Both plasma and urinary half-lives were consistent between treatment occasions and also fairly similar between subjects, ranging from 32 to $4 \mathrm{I}$ hours. There was no evidence of difference of plasma elimination half-life in the steady state compared with single dose occasions.

There was no correlation between steady state plasma concentration and either body weight or creatinine clearance. Further there was no significant relation between urinary elimination half-life and steady state plasma concentration $(r=0.31$,

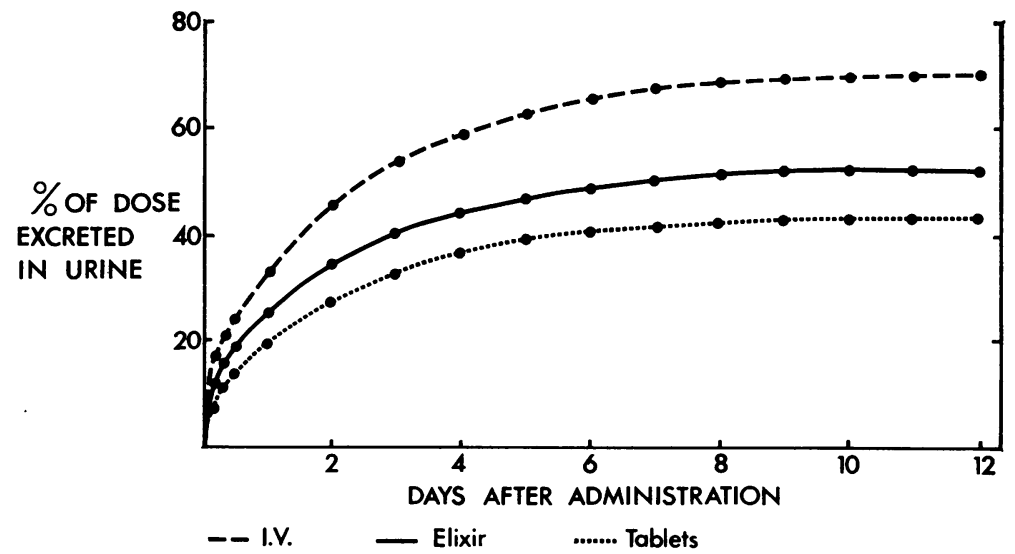

FIG. 4 Mean cumulative urinary excretion of digoxin shown as a percentage of the administered dose compared after paediatric elixir, 'lanoxin' tablets, or intravenous injection. 


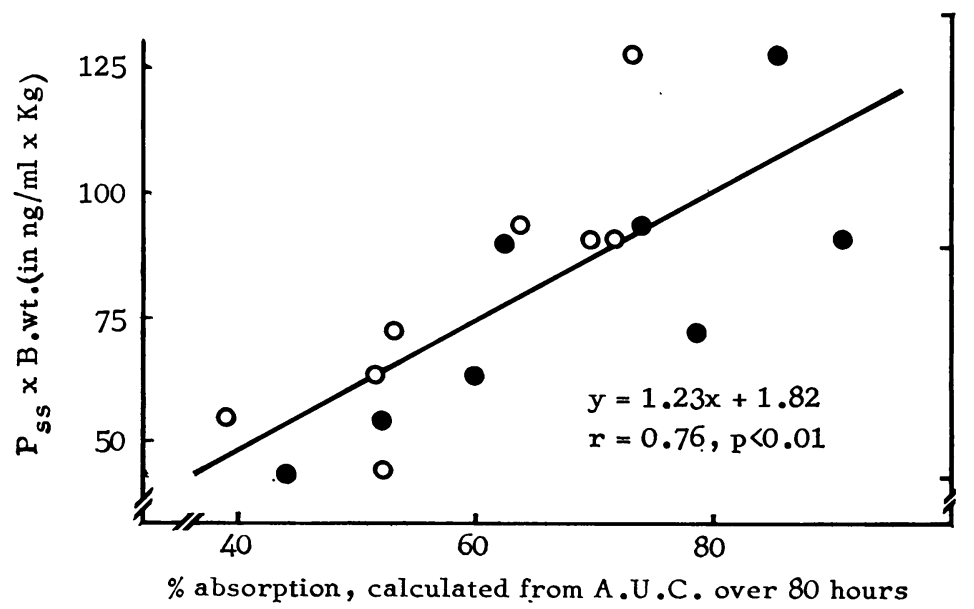

FIG. 5 Correlation of percentage intestinal absorption against steady state plasma digoxin concentration $\left(P_{\mathrm{ss}}\right)$ while taking 'lanoxin' tablets, corrected for body weight (B.wt). Percentage absorption was calculated by comparing areas under plasma concentration curves (AUC) after intravenous injection with those after I $\mathrm{mg}$ (open circles) or I.5 $\mathrm{mg}$ (filled circles) of standard 'lanoxin' tablets.

$P>0.05)$. However, there were significant correlations between steady state plasma concentration and measures of individual percentage absorption of digoxin from tablets. When percentage absorption was calculated by comparisons of values of 5 days urinary excretion after both single doses of standard tablets with those after intravenous injection, a significant correlation against plasma concentration was noted $(y=0.015 x+0.26 ; r=0.68, P<0.01)$. When percentage absorption was calculated by comparison of measurements of area under the plasma concentration curve, a correlation of $\mathbf{r}=0.70(\mathbf{P}<0.01)$ was obtained. As shown in Fig. 5, correcting steady state plasma concentration for differences in body weight tended to improve the correlation, despite the observation that body weight was not significantly correlated with plasma concentration.

\section{Discussion}

Renewed interest in the absorption of digoxin followed the demonstration of large variations in the bioavailability of digoxin from tablets (Lindenbaum et al., 1971; Manninen, Melin, and Härtel, I971). To assess fully the relative bioavailability of various preparations, it is necessary to know the maximal possible percentage absorption of digoxin. However, there are many difficulties in estimating percentage absorption. After ingestion of an alcoholic solution of tritiated digoxin, approximately 30 per cent of the radio-label was not recoverable in chloroform extracts of excreta (Doherty et al., 1961). Large between-subject variation was seen, but mean recoveries of 46 and 27 per cent were achieved in urine and stools, respectively. After demonstrating that much of the chloroformextractable tritium label in stools was excreted in bile, it was estimated that 85 per cent of ingested digoxin was absorbed (Doherty et al., 1970). This figure seemed too high, however, as the same workers reported much higher percentage urinary recovery of radioactivity after intravenous than after oral administration. None the less, using radioimmunoassay to determine urinary digoxin, a closely similar percentage urinary excretion of administered dose was reported after intravenous or oral administration of 'lanoxin' injection fluid in four volunteers (Huffman and Azarnoff, 1972). It was suggested that digoxin in alcoholic solution was almost Ioo per cent absorbed. By contrast, similar studies by other investigators resulted in calculations of 65 per cent absorption for elixir (Greenblatt et al., 1973). The difference between these contrasting results can be completely accounted for by the percentage urinary excretion of injected digoxin in the former study (Huffman and Azarnoff, I972), which was well below other reported values. Our experiments show that there is considerable betweensubject variability in absorption, but confirm that digoxin is incompletely absorbed even in alcoholic solution. It is suggested that maximal percentage digoxin absorption varies between 57 and 96 per cent, with a mean of 75 per cent. The digoxin in 
'lanoxin' tablets currently being manufactured in England is slightly less bioavailable than that in elixir, percentage absorption varying between 44 and 82 per cent in different subjects. When the mode of digoxin preparation for a child is changed from elixir to 'lanoxin' tablets, no alteration in dosage should be necessary. However, increased nominal dosage of low dissolution rate tablets must be prescribed to maintain the same level of digitalization.

In unpublished experiments from these laboratories, a solution of digoxin in water showed bioavailability equal to standard 'lanoxin' tablets, in contrast with elixir. In both elixir and water solution the digoxin must be considered to be maximally and instantly available. Possibly digoxin transport is facilitated by the alcohol or propylene glycol content of elixir. The major difference was presumably in rate of absorption, as elixir produced much larger peak plasma concentrations within an hour of ingestion. A water solution provides digoxin immediately available for normal intestinal transport systems, and is the best standard for bioavailability comparisons of other oral preparations as it avoids the possible complication of solventfacilitated absorption.

After the relation of steady state plasma concentration to clinical efficacy and toxicity (Chamberlain $e t$ al., I970; Redfors, 1972) was shown, computer programmes were designed to calculate the daily digoxin dose which would produce a required steady state concentration (Jelliffe, Buell, and Kalaba, I972; Sheiner, Rosenberg, and Melmon, 1972). These regimens require an estimate of volume of distribution (e.g. body weight or lean body mass) and an estimate of elimination rate (e.g. creatinine clearance, blood urea). It is claimed that use of such programmes may help to reduce the incidence of adverse reactions, and in 95 per cent of patients will sustain body digoxin stores at 73 to I50 per cent of the selected level (Jelliffe et al., I972). By contrast others have found them capable of gross approximations only (Peck et al., 1973), the 95 per cent confidence limits for a predicted plasma concentration of $\mathrm{I} \mathrm{ng} / \mathrm{ml}$ ranging from $O$ to $2 \cdot \mathrm{I} \mathrm{ng} / \mathrm{ml}$. This limitation is explained by the considerable individual variation in intestinal absorptive capacity. In our group of subjects with normal renal function, elimination rates were highly similar, and other sources of variability were, therefore, more apparent. Absorptive capacity will be less important in a population with a wide range of renal function. In patients requiring digoxin, administered dose and renal function are important factors in determining plasma concentration and clinical response. However, as any individual patient's absorptive capacity is unlikely to be known, precise clinical supervision would require periodic laboratory determination of plasma concentration. As the steady state plasma concentration on a given preparation of digoxin is related to the patient's absorptive capacity, it will provide a rough guide to the dose of any alternative preparation, assuming that the relative bioavailability of the preparations is known.

\section{References}

Chamberlain, D. A., White, R. J., Howard, M. R., and Smith, T. W. (1970). Plasma digoxin concentrations in patients with atrial fibrillation. British Medical fournal, 3, 429.

Doherty, J. E., Flanigan, W. J., Murphy, M. L., Bulloch, R. T., Dalrymple, G. L., Beard, O. W., and Perkins, W. H. (I970). Tritiated digoxin XIV. Enterohepatic circulation, absorption, and excretion studies in human volunteers. Circulation, 42, 867.

Doherty, J. E., Perkins, W. H., and Mitchell, G. K. (196I). Tritiated digoxin studies in human subjects. Archives of Internal Medicine, 108, $53 \mathrm{r}$.

Gold, H., Cattell, M., Greiner, T., Hanlon, L. W., Kwit, N. T., Modell, W., Cotlove, E., Benton, J., and Otto, H. L. (1953). Clinical pharmacology of digoxin. fournal of Pharmacology and Experimental Therapeutics, 109, 45.

Greenblatt, D. J., Duhme, D. W., Koch-Weser, J., and Smith, T. W. (1973). Evaluation of digoxin bioavailability in single-dose studies. New England fournal of Medicine, 289, 651.

Huffman, D. H., and Azarnoff, D. L. (1972). Absorption of orally given digoxin preparations. Fournal of the American Medical Association, 222, 957.

Jelliffe, R. W., Buell, June, and Kalaba, R. (1972). Reduction of digitalis toxicity by computer-assisted glycoside dosage regimens. Annals of Internal Medicine, 77, 891.

Johnson, B. F., Greer, H., McCrerie, J., Bye, Carole, and Fowle, A. (1973). Rate of dissolution of digoxin tablets as a predictor of absorption. Lancet, I, I473.

Lader, S., Court, G., Johnson, B. F., and Hurn, B. A. L (1972). Radioimmunoassay of digoxin with iodinated tracer. Scandinavian fournal of Clinical and Laboratory Investigation, 29, Suppl. I26.

Lindenbaum, J., Butler, V. P., Murphy, J. E., and Cresswell, R. M. (1973). Correlation of digoxin-tablet dissolutionrate with biological availability. Lancet, 1, I215.

Lindenbaum, J., Mellow, M. H., Blackstone, M. O., and Butler, V. P. (197I). Variation in biological availability of digoxin from four preparations. New England fournal of Medicine, 285, 1344 .

Manninen, V., Melin, J., and Härtel, G. (I97I). Serumdigoxin concentrations during treatment with different preparations. Lancet, 2, 934.

Peck, C. C., Sheiner, L. B., Martin, C. M., Combs, D. T., and Melmon, K. L. (1973). Computer-assisted digoxin therapy. New England fournal of Medicine, 289, 441.

Redfors, A. (1972). Plasma digoxin concentration - its relation to digoxin dosage and clinical effects in patients with atrial fibrillation. British Heart fournal, 34, 383.

Sheiner, L. B., Rosenberg, B., and Melmon, K. L. (1972). Modelling of individual pharmacokinetics for computeraided drug dosage. Computers and Biomedical Research, 5, 44I.

Requests for reprints to Dr. Brian Johnson, Department of Clinical Pharmacology, The Wellcome Research Laboratories, Langley Court, Beckenham, Kent BR 3 3BS. 